\section{The Controversial COVID-19 Pandemic: Across Europe and the United States of America}

\author{
Saira Jahangir ${ }^{1}$, Muhammad Rashid $^{2}$, Zaid Nairoukh ${ }^{1}$ and Dennis \\ Adjepong $^{3 *}$
}

${ }^{1}$ California Institute of Behavioural Neuroscience \& Psychology, USA

${ }^{2}$ Punjab University College of Information Technology, Pakistan

${ }^{3}$ Department of Neurological Surgery, California Institute of Behavioral Neurosciences \& Psychology, Fairfield, USA

\begin{abstract}
The COVID-19 Pandemic has become a controversial affair for the last couple of months. The virus has infected millions and killed hundreds of thousands of people around the world. This article aims to discuss different COVID-19 cases across the globe and share some exciting discoveries about the virus. The numeric information is taken from the original data sets available on Kaggle, accessed through links given in this research work. This research demonstrates the total number of COVID-19 cases in the U.S. and European countries. The total number of U.S. cases has grown up to two million (2.025164M). Due to this Pandemic, the death rate has increased across the globe. In European countries, the United Kingdom stands on top with a total of thirty-four million (34.078k) deaths. In this article, we present you some risk factors of Covid-19 and how to prevent an infection. Every Pandemic can heal if we look deeper into it. The vaccines and precautions can help deal with such viruses up to a great extent. Non-medical safeguards such as social distancing and lockdown measures worldwide help reduce this Pandemic as much as possible. The non-pharmaceutical methods of prevention reduced transmissibility by a maximum of $34 \%$ without resorting to a strict lockdown strategy. Infection control practices have improved over time due to these measures.
\end{abstract}

\section{Introduction}

Several pandemics have affected the human race. Among them include the plague pandemic in1855, which killed an estimated twenty-five million (25M), and Spanish flu in 1981, which infected one-third of the world's population. However, humans fought against

*Corresponding author: Adjepong Denni, Department of Neurological Surgery, California Institute of Behavioral Neurosciences \& Psychology, Fairfield, United States; E-mail: adjepongdennis1@gmail.com

Citation: Jahangir S, Rashid M, Nairoukh Z, Adjepong D (2021) The Controversial COVID-19 Pandemic: Across Europe and the United States of America. J Surg Curr Trend Innov 5: 048.

Received: March 19, 2021; Accepted: April 16, 2021; Published: April 22, 2021

Copyright: @ 2021 Jahangir S, et al. This is an open-access article distributed under the terms of the Creative Commons Attribution License, which permits unrestricted use, distribution, and reproduction in any medium, provided the original author and source are credited. these pandemics and finally won. Recently the new advanced health system was able to control the SARS (Severe Acute Respiratory Syndrome) in 2002) and MERS (Middle East Respiratory Syndrome) in 2012 epidemics by early isolating and treatment of affected patients.

However, the COVID-19 Pandemic, which started in Wuhan, China, in December 2019, affected more than 14 million people and was responsible for more than six hundred thousand $(600,000)$ deaths [1]. It is still alerting our life in many aspects, and the end of this Pandemic is not going to end soon.

COVID-19 Pandemic seems stronger than our health system. This virus won the first battle of the war; some features of this infectious disease, like long incubation period, highly contagious, the new style of our human life that contains easy travelling and lots of social communication [2]. This war is still on, and scientists have recently found some hope in some medications $[3,4]$. A new vaccine that effectively prevents the infection and may be available in the next few months [5], and more knowledge about the mode of transmission helps us avoid the spread of this Pandemic [6].

In this paper, we summarize what we have known about this virus. We compared the U.S. situation and the European situation. We discussed the mode of transmission, incubation period, environmental stability, viral genome origin, and possible mutation in this genome. Finally, we summarize the available method of management and treatment.

\section{Discussion}

In 2020 the coronavirus pandemic altered the lifestyle for many across the world. It is unclear when and how to resume daily activities as there are many challenges to overcome. In late 2019, the Coronavirus outbreak originated in Wuhan, China, and in March, it became and officially a pandemic. The virus, SARS-COV2, has infected millions and killed hundreds of thousands worldwide [7].

Positive cases of Coronavirus currently are about 2.5 million. Nearly a quarter of the global cases confirmed in the United States. In late March, the situation for COVID-19 got terrible in the United States. Many cases were declining in May, as most states across the United States placed lockdown orders. At the end of May, some parts of the United States began to ease restriction again, and some cases started to increase [8]. The United States tops with a total of two million (2.025164M) cases (last updated on April 28, 2020). This evidence is from the Data Set by Johns Hopkins accessible free on Kaggle [9].

According to COVID-19 global forecasting week 4 Data Set, the new confirmed cases have been increasing daily around the state and increases by twenty-four million (24.385k) daily (last updated April $26,2020)$. With this massive amount of confirmed cases, the U.S. is part of the top 5 countries with a total one million $(1.442653 \mathrm{M})$ confirmed cases (last updated May 10, 2020) including other countries like Italy, Russia, Spain, and United Kingdom [10]. 

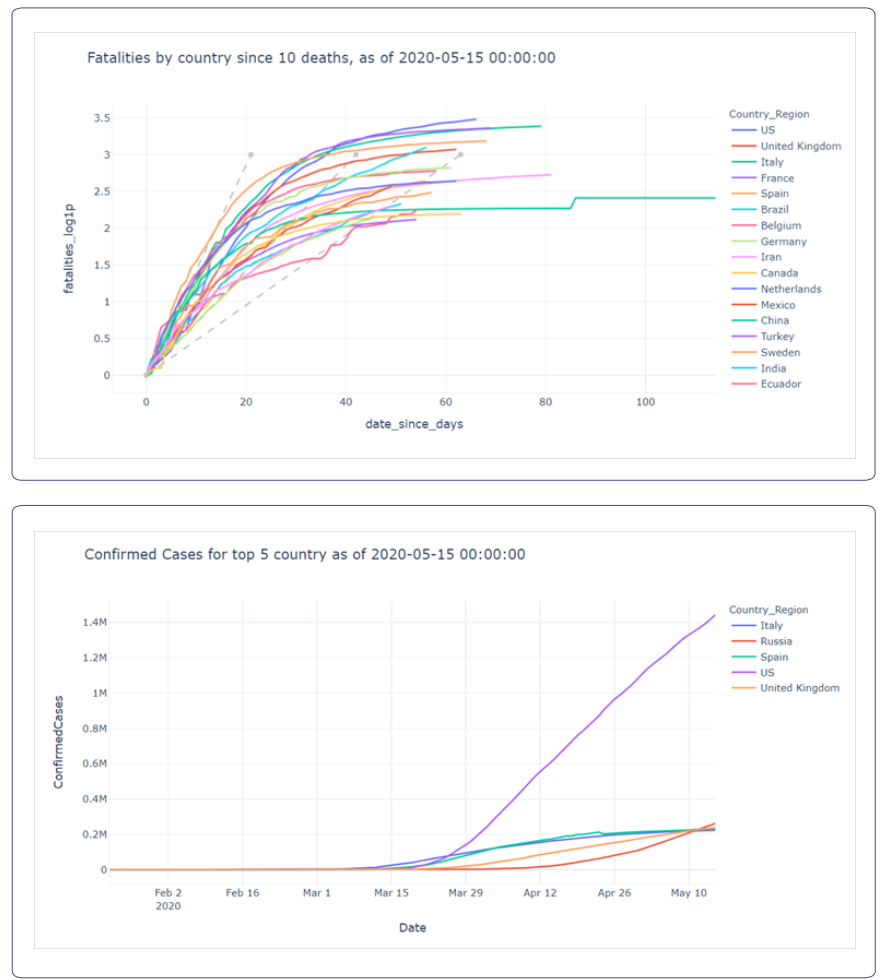

In recent weeks, these States brought outbreaks under control [8]. Public Health experts warned that the U.S. death toll could surge to 200,000 over the summer if unprecedented stay-at-home orders, closed businesses that kept most Americans indoors activities lifted after 30 days. However, most of the present restrictions on public life, including school closures and emergency orders keeping non-essential workers confined to their homes, flow from powers vested in state governors, not the president [11]. Many hospitals across south and west were flooded with patients having symptoms of COVID-19. This surge in the patient numbers forced hospitals to cancel elective surgeries and many patients were discharged earlier to keep more beds available. Even regular wards were converted into intensive care units and long-term care facilities are open for patients who are too sick to go home and are barely managing their condition [12]

\section{Europe Situation}

In Europe, the number of new deaths and infections of COVID-19 declines daily though there was a huge outbreak in the Pandemic. It is a promising sign of bringing hope to the continent. As of March 13, 2020, the new cases grew more than those of China. Due to these new cases, the World Health Organization (WHO) recognized Europe as the active focus of the COVID-19 Pandemic. As of March 18, 2020, more than 250 million people remained in lockdown across Europe. As of May 24, 68 days since its first recorded case, Montenegro became the first COVID-19-free country in Europe, but this situation lasted only 44 days before newly imported cases identified in Europe [13].

While European countries begin planning and carefully implementing measures to ease lockdown, the scale of the COVID-19 Pandemic on the global economy started to impact and difficulties to be precisely quantified. Throughout faced challenges, businesses were defined by shifting consumers' preferences and expectations and new public health concerns and approaches. Governments began various measures to boost the economy and mitigate the impact of the outbreak [14]. The following data taken from the data set COVID-19 global forecasting week four accessible on Kaggle [10] (Graph no. 9).

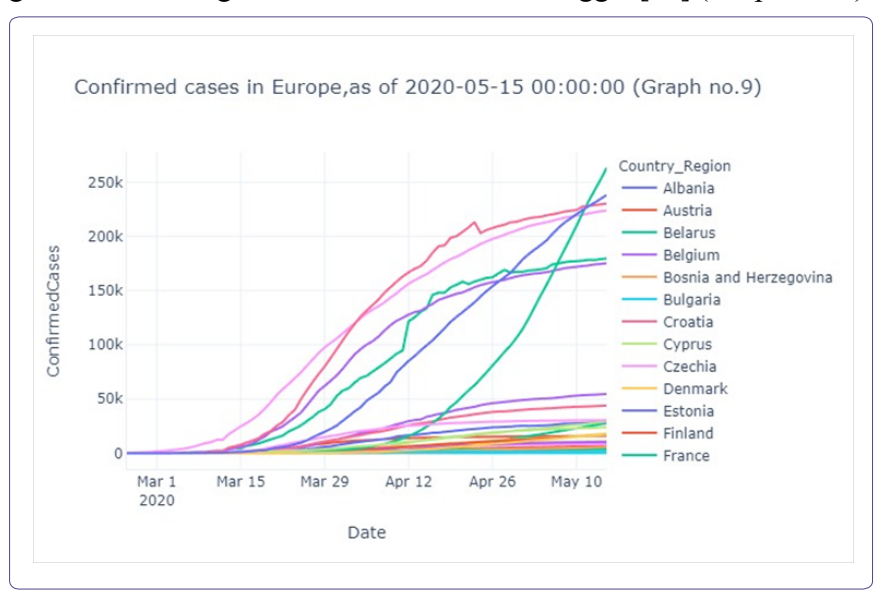

The resulting data is representing confirmed cases in several countries of Europe. Russia, the most affected country with a total of two hundred and sixty-two million (262.843k), as displayed in the data. The United Kingdom in Europe was the second most affected country with a total of two hundred and thirty-eight million (238.004k) confirmed cases. Spain appears in the third place, with a total of two hundred thirty million $(230.183 \mathrm{k})$ confirmed cases across the continent. Additional states with approximately the same confirmed cases include Italy, France, and Germany. On May 15, 2020, this data refreshed [10] (Graph no. 10).

Fatalities in Europe, as of 2020-05-15 00:00:00 (Graph no.10)

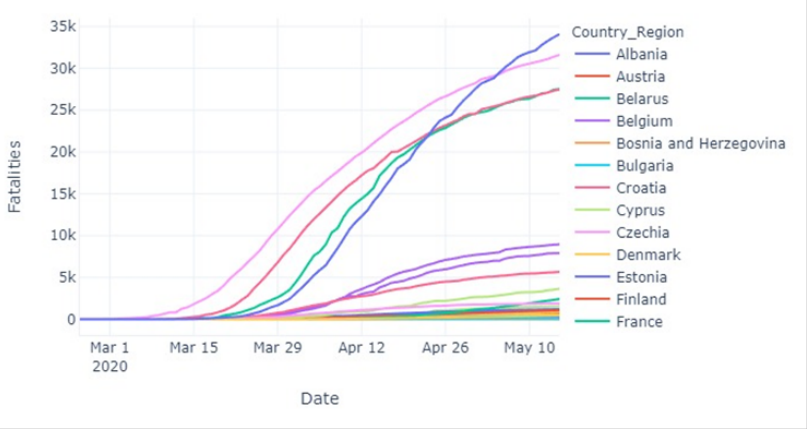

Amidst the growing numbers of confirmed cases, the fatalities increased at a tremendous pace. According to COVID-19 global forecasting week, United Kingdom stands on top with a total of thirty-four million (34.078k) deaths. The second most fatalities occur in Italy, including a total of three million and $31.61 \mathrm{k}$ in numbers. France and Spain reached the third-highest number of deaths, with a total of twenty-seven million (27.532k) and twenty-seven million (27.459k). This data was also last updated on May 15, 2020 [10]. Europe is mobilizing all resources to support member states to coordinate their national responses. Providing objective information about the spread of the virus, the active efforts to contain it, and steps used to improve the economic and social damage produced by the pandemic [15].

\section{What do we know about transmission, incubation, and en-} vironmental stability?

Asymptomatic carriers are the most common source of transmission. We observed that several studies recommended 
serology analysis to diagnose COVID-19. Asymptomatic infections discovered among people in Wuhan China were used to design adequate public health measures. We found that clinical data got collected and analyzed in the Wuhan General Hospital mandatory for 16 to 64-year-old asymptomatic people. It is a retrospective study that estimates seroprevalence of IgM and IgG. In this study, these seroprevalences analyzed the epidemiological characteristics of the asymptomatic SARSCOV-2 infected population. From the Wuhan General Hospital between March 26 and April 28, 2020, many demographic and radiologic data were collected for this study [16]. This information is taken from the article given

\begin{tabular}{|c|c|c|c|}
\hline pub_date & authors & title & excerpt \\
\hline $\begin{array}{l}2020- \\
06-19\end{array}$ & $\begin{array}{l}\text { Ling, et } \\
\text { al. }\end{array}$ & $\begin{array}{l}\text { Seroprevalence } \\
\text { and } \\
\text { epidemiological } \\
\text { characteristics } \\
\text { of } \\
\text { immunoglobulin } \\
\text { M and G } \\
\text { antibodies } \\
\text { against SARS- } \\
\text { CoV-2 in } \\
\text { asymptomatic } \\
\text { people in } \\
\text { Wuhan, China }\end{array}$ & $\begin{array}{l}\text { Based on the census population aged } 16-64 \text { years in wuhan in } 2017 \text {, we } \\
\text { estimated that } 172,340 \text { ( } 95 \% \text { ci: } 157,568-187,112 \text { ) asymptomatic } \\
\text { people aged } 16-64 \text { years were infected with sars-cov- } 2 \text { in wuhan } \\
\text { between march } 25 \text { and april } 28,2020 \text {. }\end{array}$ \\
\hline
\end{tabular}

Other ways of transmission include droplets transmission through mouth and nose, contact spread through table, chairs, and handles, aerosol transmission, i.e, air, fecal-oral route transmission, and mother-to-child transmission. All these sources of communication require social interaction, and thus, isolating oneself is one of the ways to be safe from the virus. All the information about transmission has been taken from the notebook available on Kaggle [17]

Once the virus is transmitted, then comes a period of incubation. Evaluating the severity of the infection is estimated by the specified reproduction number (denoted $\mathrm{R} 0$ ). In a population, the average number of cases is generated by an infected individual where everyone is susceptible to infection, which is defined by the reproduction number. We discovered that many studies estimated the first reproduction number to be 3.15 with the $95 \%$ CI (2.41-3.90), the average incubation time to be 5.08 days with the $95 \%$ CI (4.77-5.39) (in a day), the asymptomatic infection rate to be $46 \%$ with the $95 \%$ CI (18.48\%-73.60\%), and the case fatality rate to be $2.72 \%$ with $95 \%$ CI (1.29\%-4.16\%). Here having no infections or symptoms account for estimation of the required reproduction number, mean incubation time, asymptomatic infection rate, and the case fatality rate for COVID-19: meta-analysis and sensitivity analysis [18]. The information has been taken from the given article available on Kaggle.

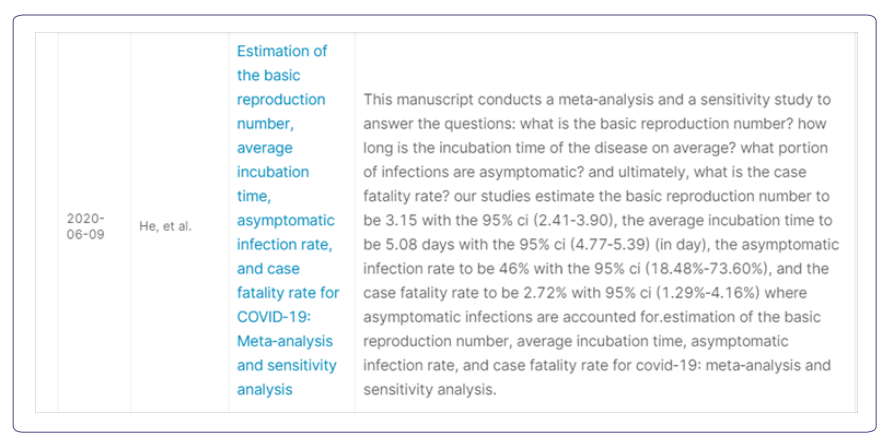

Transmission for COVID-19 is mainly through close contact and respiratory droplets. The fecal-oral transmission has not been ruled out yet. It is crucial to find how acidic stomach fluid affects the infectivity of this virus. Under the dry or wet conditions, the stability of the COVID-19 virus is still not well understood. Shown in a present study about the infectivity, which is exceptional as manifested by Vero-E6 cell infection, which is caused by the Plaque Forming Unit (PFU) of the virus. The stability is further investigated in wet, dry, and acidic with a P.H. of 2.2 environments. The results for the dry condition are less favorable for the virus to survive. However, the COVID-19 virus could survive for three days in damp and dry climates. Further studies can be found in a given article [19]. Further studies can be found in a given section.

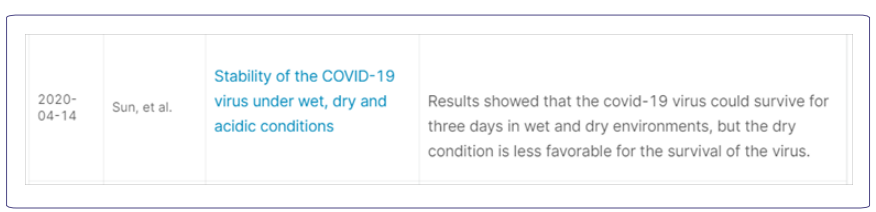

The persistence of this virus detected on inanimate surfaces varied from minutes to up to one month, depending on the environmental condition. In closed unventilated buses, the COVID-19 infection survives for at least 30 minutes without losing its infectivity. The most common coronaviruses may well survive or persist on surfaces for up to one month. Viruses in respiratory or fecal specimens can maintain infectivity for quite a long time at room temperature. The infected patient remains in the ward; the virus exists in the air due to respiratory droplets. The half-life of coronaviruses in aerosols was reported to be eight hours at $80 \%$ humidity in the environment [20]. Further data can be found in the following article available on the Kaggle link [17].

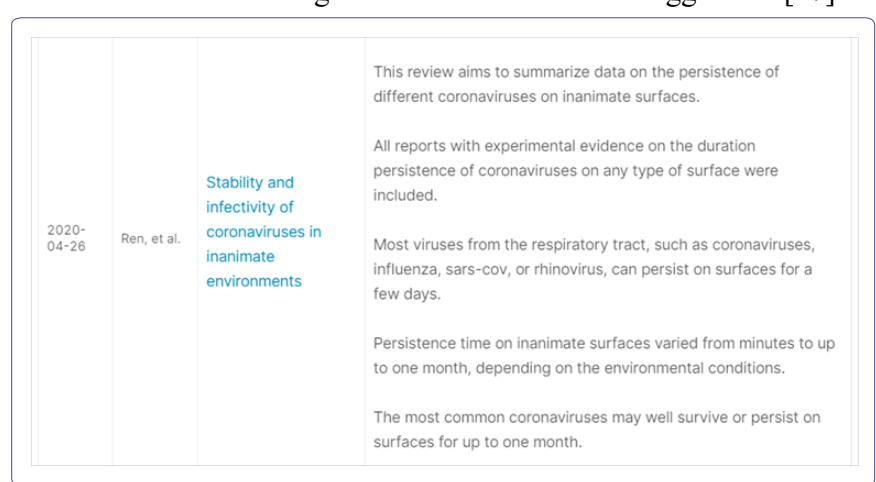

\section{What is known about COVID-19 risk factors?}

A risk factor doubles the likelihood of being infected or influences the severity or the survival outcome of the infection. There are various risk factors associated with COVID-19. One of the risk factors is having heart risk and diseases. COVID-19 severity is more likely to worsen if the patient also has chronic diseases like coronary heart disease, hypertension, and diabetes [21].

\begin{tabular}{|c|c|c|c|}
\hline 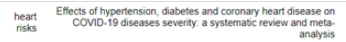 & [rean tosesese? & $"$ & 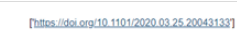 \\
\hline
\end{tabular}

Further data can be read from the articles available on it. Studies have found that people with older age (60 or above) are at higher-risk for COVID-19. The following report indicates the fatality ratio across the spectrum of COVID-19 disease, and there is a strong correlation with age being of the risk factor in the death [22].

Humidity is an added risk factor associated with COVID-19. The respiratory droplets are the main route of transmission of COVID-19 
$$
\underset{\substack{\text { IId } \\ \text { Age }}}{ }
$$

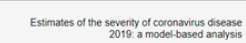

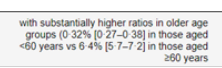

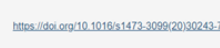

infection. However, through other body fluids and excreta, this virus is also detected. At different temperatures and smooth surfaces were studied to find the stability factor for COVID-19. The dried virus found on the flat surface retains its viability for greater than 5 days when the temperature is around $22-25^{\circ} \mathrm{C}$. Also, the humidity of 40 $50 \%$, typical air-conditioned environments, plays a role in the stability of COVID-19 [23].

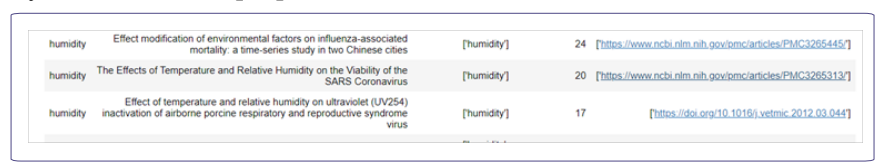

Air pollution also presents a vital impact when someone is infected with COVID-19. Most data originate from temperate regions. The studies demonstrated a positive association between air pollution and virus case fatality in the Chinese population by utilizing publicly accessible data on SARS statistics and air pollution indices. Air pollution has wide-ranging systemic effects on the human body, impacting both the respiratory and cardiovascular systems via multiple mechanisms, including oxidative stress, inflammation, and endothelial dysfunction [24].

\begin{tabular}{|c|c|c|c|}
\hline polution & 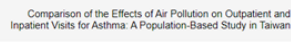 & 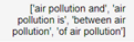 & 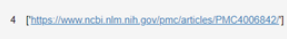 \\
\hline pollution & 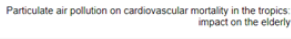 & 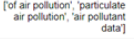 & 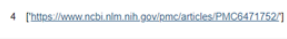 \\
\hline
\end{tabular}

We found that environments such as seasonal climates strongly impacted spatiotemporal patterns of an infectious disease outbreak. However, the relationship between COVID-19 dynamic and atmosphere remains controversial. The temperature has an essential effect on viral activity, particularly in the case of enveloped viruses. Most reports on viral seasonality concentrate on infections that appear in the winter months. Studies have found that COVID-19 was significantly lower in warm climate countries and has high-risk factors in cold regions. There is a strict lockdown in countries with a cold climate [25].

\begin{tabular}{|c|c|c|c|c|}
\hline temperature & 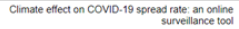 & [cimate] ] & 38 & 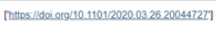 \\
\hline
\end{tabular}

Population density also takes part in the COVID-19 risk factor. Density is likely just one of several key factors that determine how vulnerable places are to the virus.

Density probably leads to an increase in the contact rate of an individual, making the reproduction number larger and leading to more massive infectious disease outbreaks in dense areas. The following studies show the involvement of population density in various pandemics. Geographic variables play an essential role in the study of epidemics. The population density, in the spread of influenza is controversial. Many prior studies have tested for using arbitrary thresholds for population density above or below. These thresholds are hypothesized to have higher or lower mortality. The results of such studies are mixed. This study's objective is to estimate, rather than assume, a threshold level of population density that separates low-density regions from high-density regions based on population loss during an influenza pandemic [26].

\section{What is known about virus genetics, origin, and evolution?}

The following data about virus genetics, origin, and evolution is taken from the notebook available on Kaggle. The link is given as https://www.kaggle.com/jahangirs/covid-19-results

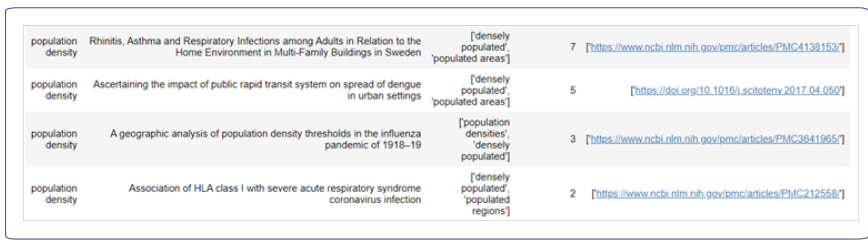

Viruses evolve by mutating. There are changes in their genetic code over time. Some viruses transmit from wildlife to humans or domestic animals. The COVID-19 virus is a new type of batcoronavirus. It is genetically reasonably distant from the human SARS coronavirus. When performed the structure analysis, we discovered the Spike (S) the protein of this new virus showed that the $\mathrm{S}$ protein only binds weakly to the ACE2 receptor on human cells. The human SARS coronavirus actively exhibits an affinity to the ACE receptor. We discovered that these findings suggest a new virus does not transmit between humans and theoretically not able to cause serious human infections. This shows that the virus can easily be transmitted through animals. Further information can be read from the article available on the given link [27].

Task 3: What do we know about virus genetics, origin, and evolution?

1. can animals transmit 2019-ncov?

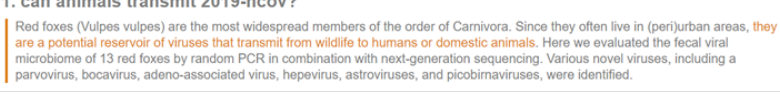

The emergence of COVID-19 reminds us once again of the importance of establishing a systematic coronavirus surveillance network. The prevention and control department facing new challenges in controlling the epidemic and providing rapid response to scientific research.

The Human Coronavirus (HCOV) contains HCOV-229E, HCOVNL63, HCOV-OC43, HCOV- HKU1, SARS-COV, and MERS-COV. HCOV-229E, HCOV-NL63, HCOV-OC43, and HCOV-HKU1, pathogens of the common cold. During 2002-2003, a new coronavirus, the SARS-COV, caused an acute, severe, frequently fatal respiratory disease with prominent systemic symptoms. The outbreak originated in southern China, probably the following transmission from an animal in animal markets or bats to humans. The first occurrence of coronavirus disease 2019, some online tools have become available to assist with tracking Covid-19 prevalence. Agencies, such as public health, provide real-time infection tracking tools that report country-specific COVID-19 incidence metrics and prevalence data. Further data regarding mechanisms are available on a given link and article [27].

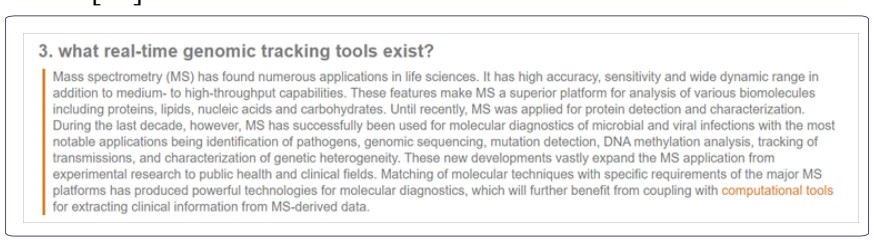

In 2002-2003, a novel pathogen severe acute respiratory syndrome, SARS, as an epidemic emerged. Future outbreaks prevention is essential and requires understanding the pathogenesis and development of the virus. The presence of SARS-COV was determined by RT-PCR and confirmed by electron microscopy. The virus was isolated, followed by the determination of its genome sequences, which were then analyzed by comparing it with other 46 SARS-COV genomes. As the infection of $2019-\mathrm{nCoV}$ Coronavirus is quickly 
developing into a global pneumonia epidemic, the careful analysis of its transmission and cellular mechanisms is sorely needed. [27].

To prevent future outbreak, various measures have been taken. In developing countries of Asia, there is continuous and close contact between animals and humans, especially in rural settings. Many healthcare systems faced challenges. They are compelled both national and international levels to have a better framework for preparedness, outbreak response, and recovery. To have a better framework, a thorough review done by the World Health Organization, Center for Disease Control and Prevention, and the Malaysian framework. These reviews were done to identify specific components and replicable objectives to the national context [27]. Further measures and actions can be read from the given article available on Kaggle [27].

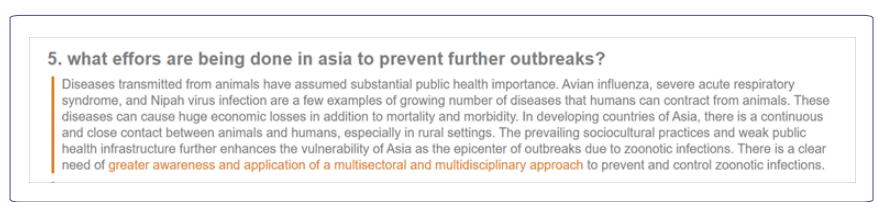

\section{What do we know about vaccines \& therapeutics?}

No effective therapy for COVID-19 is available currently. Here we discuss the drugs that have been investigated for the treatment of the disease. All the listed therapies are at experimental at this stage. However, due to the severe healthcare effects of the Pandemic and the potentially fatal outcome of COVID-19 patients treated in intensive care units, their off-label use should be considered. Further information about the drugs being used to manage the virus can be known from the notebook available on Kaggle [27]. The link is given as https:// www.kaggle.com/jahangirs/covid-19-results

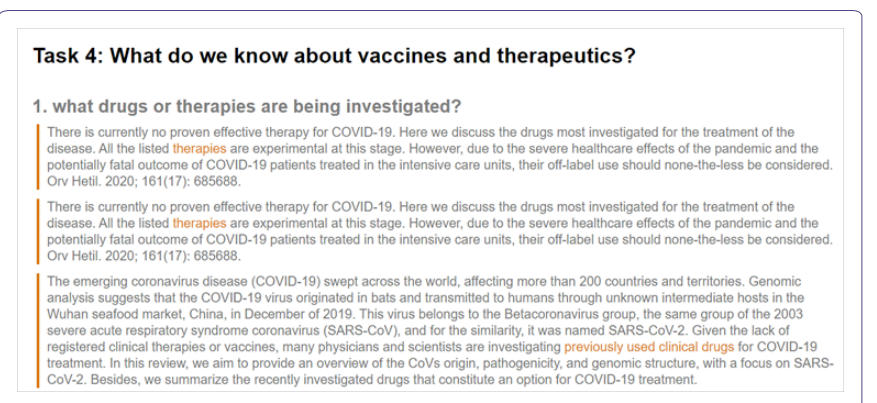

The treatment for COVID-19 is being investigated, including the use of antivirals and different therapies, targeting several complications from COVID-19. Mild fever, cough, dyspnea, and some complications such as Acute Respiratory Distress Syndrome (ARDS), systemic hyper inflammation, and sepsis. Understanding pathogenesis and complexity are essential in developing effective therapies to treat potentially life-threatening diseases [27].

Targeting RNA respiratory viruses, many drugs result in few effective therapies. Many antiviral highlights the challenge of treating COVID-19. Unfortunately, few accurate data support these antivirals, which targeting symptomatic COVID-19 [27].

Rodents host many segmented genome RNA viruses, arena viruses, and hantaviruses. These viruses can infect humans via direct or indirect transmission routes, which has to lead to human morbidity and mortality. Despite this emerging importance of these pathogens, currently, no effective antiviral drugs except Ribavirin proved effective against Lassa Virus [27].
There is an active global health threat by the Coronavirus disease 2019 (SARS-CoV2), for which treatment is being explored. Most people infected with mild to moderate symptoms, and they do recover with supportive care, and many do manifest severe clinical signs [27].

Few effective therapies, targeting RNA respiratory virus have resulted which highlight challenges for antiviruses to treat COVID-19. These antiviral treatments under investigation for symptomatic COVID-19 but unable to find definitive data to support their clinical use. However, Remdesivir, in vitro with good activity found against SARS-CoV2, results in favorable outcomes mostly for hospitalized patients. Remdesivir, in a compassionate use series, has shortened the time of recovery and helped decrease the mortality of severely compromised patients. Currently, in phase III clinical trials, Remdesivir under compassionate use and through Emergency Use Authorization (EUA) [27].

Mast-Cell stabilizers, Nedocromil prevents or ablates the acute and late phase of allergic response. Nedocromil is not a steroid but an inflammatory agent for pulmonary administration. Its nasal form is under clinical trials and not yet released in the United States [27].

\section{What do we know about non-pharmaceutical interven- tions?}

Some non-pharmaceutical interventions have been discovered due to Covid-19. Social distancing and lockdown protocols have taken place around the globe. Non-pharmaceutical, estimated to reduce transmission by a maximum of $34 \%$ without resorting to a strict lockdown strategy. To optimize epidemic control, continuous efforts to monitor the transmissibility are needed [27]. The data has been taken from a notebook available on Kaggle. The link is given as https:// www.kaggle.com/jahangirs/covid-19-results

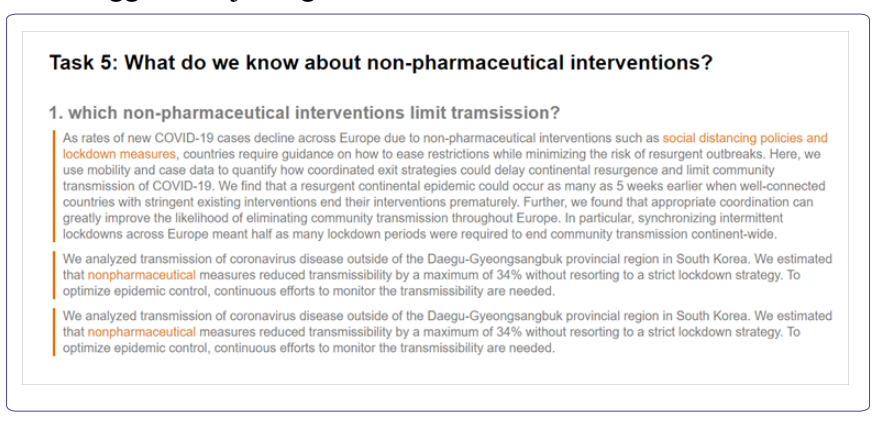

It is particularly noteworthy with a growing HIV/AIDS epidemic for the health service providers in China to recognize and correctly adhere to universal precautions. Many of China's healthcare system workers, utilizing qualitative interview data and perspective from health administrators and service providers, were also examined [27]. A continuous effort is required to monitor the transmissibility and to control this epidemic [27].

Great efforts by hospital authorities and hospital clusters, were studied to contain and prevent infection. To prevent the outbreak of SARS and other droplet infection, a high level of vigilance was enforced. To follow hospital infection control and isolation precautions, most of the health workers recognized and followed hospital infection control and isolation precautions. When compared with previous studies, compliance with infection control guideline were detected. Most participants had positive perceptions of the instructions and found the training program useful. This study identified many 
Citation: Jahangir S, Rashid M, Nairoukh Z, Adjepong D (2021) The Controversial COVID-19 Pandemic: Across Europe and the United States of America. J Surg Curr Trend Innov 5: 048.

infection controls practices that require improving the clarity of guidelines in the field of infection and prevention control [27].

In East Asia, substantial compliance practice for infection control has not been documented. To investigate changes under recommended infection control practices over eleven years and to identify affecting factors, two nationwide cross-sectional surveys of dentists in Taiwan were conducted in 1999 and 2010 [27]. Although infection control practices have improved over time, there is room for improvement in practices such as wearing a head cap, protective eyewear, and a face mask and disinfecting impression materials. Implementing accurate measures about disinfection and sterilization methods strengthen the ability to fight from viruses [27].

\section{Conclusion}

The COVID-19 cases keep increasing daily around the globe, along with death rates as well. All primary information about COVID-19 with actual data sets is achieved in this research. We have come to know the authentic number of total cases with deaths and fatalities in various areas around the globe. The sources from which all information taken are available on Kaggle, and these data set are correctly studied. In summary, the coronavirus history and evolution are studied. In this paper, links for further articles to understand this virus is provided. Various studies and analyses holding to cure this virus of scratch are provided in this manuscript.

Although some populations have recovered from the Pandemic in some parts of the world; we need some time for the virus to be eradicated. The economy will also take time to recover. Several small businesses will try harder than usual to take their place back. It is anticipated that, the people will have to live with this virus as a new normal forever because it still doesn't know when the virus will be demolished from the world until its vaccine shows up.

\section{References}

1. Plague was one of history's deadliest diseases-then we found a cure (2020). Science.

2. Wenqing H, Yi GY, Zhu Y (2020) Estimation of the Basic Reproduction Number, Average Incubation Time, Asymptomatic Infection Rate, and Case Fatality Rate for COVID-19: Meta-Analysis and Sensitivity Analysis. J Med Virol 92: 2543-2550.

3. The Recovery Collaborative Group. Horby P, Lim WS, Emberson JR, Mafham M, Bell JL, et al. (2020) Dexamethasone in Hospitalized Patients with Covid-19 - Preliminary Report. N Engl J Med 384: 693-704.

4. Beigel JH, Tomashek KM, Dodd LE, Mehta AK, Zingman BS, et al. ACTT-1 Study Group Members. (2020) Remdesivir for the Treatment of Covid-19 - Final Report. New Eng J Med 383:1813-1826.

5. Folegatti PM, Ewer KJ, Aley PK, Angus B, Becker S, et al. (2020) Safety and immunogenicity of the ChAdOx $1 \mathrm{nCoV}-19$ vaccine against SARS CoV-2: a preliminary report of a phase $1 / 2$, single-blind, randomised controlled trial. The Lancet 396: 467-478

6. Morawska L, Cao J (2020) Airborne transmission of SARS-CoV-2: The world should face the reality. Environ Int 139: 105730.
7. (2020) Coronavirus pandemic USA: Daily COVID-19 updates and information from around the world $\mid$ Accu Weather.

8. Coronavirus: Is the Pandemic getting worse in the U.S.? (2020). BBC News.

9. (2020) Johns Hopkins: COVID-19 daily dashboard cases over time. UNCOVER COVID-19 Challenge.

10. (2020) Kaggle: COVID-19 global forecasting.

11. (2020) U.S. has highest toll from COVID-19.

12. (2020) U.S. Hits Another Record for New Coronavirus Cases. The New York Times.

13. COVID-19 Pandemic in Europe (2020). In Wikipedia.

14. (2020) E.U. countries measures on COVID-19 under magnifying glass. (n.d.). Deloitte Romania.

15. (2020) The common E.U. response to COVID-19. European Union.

16. Ling R, Yu Y, He J, Zhang J, Xu S, et al. (2020) Seroprevalence and epidemiological characteristics of immunoglobulin $M$ and $G$ antibodies against SARS-CoV-2 in asymptomatic people in Wuhan, China. MedRxiv 2020.06.16.20132423.

17. Kaggle: COVID-19 TASK -1 transmission, incubation, and environment.

18. He W, Yi GY, Zhu Y (2020) Estimation of the basic reproduction number, average incubation time, asymptomatic infection rate, and case fatality rate for COVID-19: Meta-analysis and sensitivity analysis. Journal of Medical Virology 92: 2543-2550.

19. Sun Z, Cai X, Gu C, Zhang R, Han W, et al. (2020) Stability of the COVID-19 virus under wet, dry and acidic conditions. MedRxiv, 2020.04.09.20058875.

20. Ren SY, Wang WB, Hao YG, Zhang HR, Wang ZC, et al. (2020) Stability and infectivity of coronaviruses in inanimate environments. World Journal of Clinical Cases 8: 1391-1399.

21. Chen Y, Gong X, Wang L, Guo J (2020) Effects of hypertension, diabetes and coronary heart disease on COVID-19 diseases severity: a systematic review and meta-analysis. MedRxiv, 2020.03.25.20043133.

22. Verity R, Okell LC, Dorigatti I, Winskill P, Whittaker C, et al. (2020) Estimates of the severity of coronavirus disease 2019: a model-based analysis. Lancet Infect Dis 20: 669-677.

23. Chan KH, Peiris JSM, Lam SY, Poon LLM, Yuen KY, et al. (2011) The Effects of Temperature and Relative Humidity on the Viability of the SARS Coronavirus. Adv Virol 2011: 734690.

24. Pan HH, Chen CT, Sun HL, Ku MS, Liao PF, et al. (2014) Comparison of the Effects of Air Pollution on Outpatient and Inpatient Visits for Asthma: A Population-Based Study in Taiwan. PLoS ONE 9: e96190.

25. Caspi G, Shalit U, Kristensen SL, Aronson D, Caspi L, et al. (2020) Climate effect on COVID-19 spread rate: an online surveillance tool. MedRxiv 2020.03.26.20044727.

26. Chandra S, Kassens-Noor E, Kuljanin G, Vertalka J (2013) A geographic analysis of population density thresholds in the influenza pandemic of 1918-19. Int J Health Geographics 12.

27. Kaggle: COVID-19 and our lives. 


\section{Hit \\ жram}

Advances In Industrial Biotechnology | ISSN: 2639-5665

Advances In Microbiology Research | ISSN: 2689-694X

Archives Of Surgery And Surgical Education | ISSN: 2689-3126

Archives Of Urology

Archives Of Zoological Studies | ISSN: 2640-7779

Current Trends Medical And Biological Engineering

International Journal Of Case Reports And Therapeutic Studies | ISSN: 2689-310X

Journal Of Addiction \& Addictive Disorders | ISSN: 2578-7276

Journal Of Agronomy \& Agricultural Science | ISSN: 2689-8292

Journal Of AIDS Clinical Research \& STDs | ISSN: 2572-7370

Journal Of Alcoholism Drug Abuse \& Substance Dependence | ISSN: 2572-9594

Journal Of Allergy Disorders \& Therapy | ISSN: 2470-749X

Journal Of Alternative Complementary \& Integrative Medicine | ISSN: 2470-7562

Journal Of Alzheimers \& Neurodegenerative Diseases | ISSN: 2572-9608

Journal Of Anesthesia \& Clinical Care | ISSN: 2378-8879

Journal Of Angiology \& Vascular Surgery | ISSN: 2572-7397

Journal Of Animal Research \& Veterinary Science | ISSN: 2639-3751

Journal Of Aquaculture \& Fisheries | ISSN: 2576-5523

Journal Of Atmospheric \& Earth Sciences | ISSN: 2689-8780

Journal Of Biotech Research \& Biochemistry

Journal Of Brain \& Neuroscience Research

Journal Of Cancer Biology \& Treatment | ISSN: 2470-7546

Journal Of Cardiology Study \& Research | ISSN: 2640-768X

Journal Of Cell Biology \& Cell Metabolism | ISSN: 2381-1943

Journal Of Clinical Dermatology \& Therapy | ISSN: 2378-8771

Journal Of Clinical Immunology \& Immunotherapy | ISSN: 2378-8844

Journal Of Clinical Studies \& Medical Case Reports | ISSN: 2378-8801

Journal Of Community Medicine \& Public Health Care | ISSN: 2381-1978

Journal Of Cytology \& Tissue Biology | ISSN: 2378-9107

Journal Of Dairy Research \& Technology | ISSN: 2688-9315

Journal Of Dentistry Oral Health \& Cosmesis | ISSN: 2473-6783

Journal Of Diabetes \& Metabolic Disorders | ISSN: 2381-201X

Journal Of Emergency Medicine Trauma \& Surgical Care | ISSN: 2378-8798

Journal Of Environmental Science Current Research | ISSN: 2643-5020

Journal Of Food Science \& Nutrition | ISSN: 2470-1076

Journal Of Forensic Legal \& Investigative Sciences | ISSN: 2473-733X

Journal Of Gastroenterology \& Hepatology Research | ISSN: 2574-2566
Journal Of Genetics \& Genomic Sciences | ISSN: 2574-2485

Journal Of Gerontology \& Geriatric Medicine | ISSN: 2381-8662

Journal Of Hematology Blood Transfusion \& Disorders | ISSN: 2572-2999

Journal Of Hospice \& Palliative Medical Care

Journal Of Human Endocrinology | ISSN: 2572-9640

Journal Of Infectious \& Non Infectious Diseases | ISSN: 2381-8654

Journal Of Internal Medicine \& Primary Healthcare | ISSN: 2574-2493

Journal Of Light \& Laser Current Trends

Journal Of Medicine Study \& Research | ISSN: 2639-5657

Journal Of Modern Chemical Sciences

Journal Of Nanotechnology Nanomedicine \& Nanobiotechnology | ISSN: 2381-2044

Journal Of Neonatology \& Clinical Pediatrics | ISSN: 2378-878X

Journal Of Nephrology \& Renal Therapy | ISSN: 2473-7313

Journal Of Non Invasive Vascular Investigation | ISSN: 2572-7400

Journal Of Nuclear Medicine Radiology \& Radiation Therapy | ISSN: 2572-7419

Journal Of Obesity \& Weight Loss | ISSN: 2473-7372

Journal Of Ophthalmology \& Clinical Research | ISSN: 2378-8887

Journal Of Orthopedic Research \& Physiotherapy | ISSN: 2381-2052

Journal Of Otolaryngology Head \& Neck Surgery | ISSN: 2573-010X

Journal Of Pathology Clinical \& Medical Research

Journal Of Pharmacology Pharmaceutics \& Pharmacovigilance | ISSN: 2639-5649

Journal Of Physical Medicine Rehabilitation \& Disabilities | ISSN: 2381-8670

Journal Of Plant Science Current Research | ISSN: 2639-3743

Journal Of Practical \& Professional Nursing | ISSN: 2639-5681

Journal Of Protein Research \& Bioinformatics

Journal Of Psychiatry Depression \& Anxiety | ISSN: 2573-0150

Journal Of Pulmonary Medicine \& Respiratory Research | ISSN: 2573-0177

Journal Of Reproductive Medicine Gynaecology \& Obstetrics | ISSN: 2574-2574

Journal Of Stem Cells Research Development \& Therapy | ISSN: 2381-2060

Journal Of Surgery Current Trends \& Innovations | ISSN: 2578-7284

Journal Of Toxicology Current Research | ISSN: 2639-3735

Journal Of Translational Science And Research

Journal Of Vaccines Research \& Vaccination | ISSN: 2573-0193

Journal Of Virology \& Antivirals

Sports Medicine And Injury Care Journal | ISSN: 2689-8829

Trends In Anatomy \& Physiology | ISSN: 2640-7752

Submit Your Manuscript: https://www.heraldopenaccess.us/submit-manuscript 